\title{
Review Article \\ Cervical Spondylotic Myelopathy: Factors in Choosing the Surgical Approach
}

\author{
Praveen K. Yalamanchili, Michael J. Vives, and Saad B. Chaudhary \\ Department of Orthopaedics, University of Medicine and Dentistry-New Jersey Medical School, 140 Bergen Street, \\ Suite D1619, Newark, NJ 07103, USA \\ Correspondence should be addressed to Michael J. Vives, vivesmj@umdnj.edu
}

Received 16 July 2011; Accepted 20 October 2011

Academic Editor: Joseph S. Butler

Copyright ( 12012 Praveen K. Yalamanchili et al. This is an open access article distributed under the Creative Commons Attribution License, which permits unrestricted use, distribution, and reproduction in any medium, provided the original work is properly cited.

Cervical spondylotic myelopathy is a progressive disease and a common cause of acquired disability in the elderly. A variety of surgical interventions are available to halt or improve progression of the disease. Surgical options include anterior or posterior approaches with and without fusion. These include anterior cervical discectomy and fusion, anterior cervical corpectomy and fusion, cervical disc replacement, laminoplasty, laminectomy with and without fusion, and combined approaches. Recent investigation into the ideal approach has not found a clearly superior choice, but individual patient characteristics can guide treatment.

\section{Introduction}

Cervical degenerative disease, or cervical spondylosis, is an age-related change affecting the cervical spinal column. Radiographic evidence of cervical spondylosis can be found in $85 \%$ of individuals over sixty years of age [1]. Certain occupations and activities that place increased loads on the head may have a predisposition for cervical degenerative disease. Cervical myelopathy is a clinical syndrome that may result from cervical spondylosis. When cervical myelopathy is a result of spondylosis, it is referred to as cervical spondylotic myelopathy (CSM).

Cervical spondylotic myelopathy manifests as long-tract clinical findings in the upper and lower extremities caused by spinal cord compression [2]. Patients present with a variety of findings, including clumsiness, loss of manual dexterity, difficulty with gait or balance, urinary complaints, motor weakness, sensory changes, and abnormal or pathologic reflexes. Appropriate initial imaging of CSM consists of plain static radiographs and flexion extension views to evaluate for instability. The advancing imaging of choice is magnetic resonance imaging (MRI) of the cervical spine to evaluate the soft tissues about the spine and the spinal cord. Clinical correlation is important when evaluating MRI changes as MRI can be overly sensitive and reveal abnormalities in asymptomatic adults [3]. Electrodiagnostic studies may be helpful to exclude other causes of upper extremity symptoms, such as suspected peripheral nerve entrapment syndromes.

The natural history of CSM is a progression of symptoms in a stepwise fashion over time [4]. Patients with mild myelopathy (that does not interfere with function) may be offered a trial of nonoperative management, whereas progressive, long-standing, or severe myelopathy is candidates for surgical decompression of the spinal cord in the affected areas $[5,6]$. Operative intervention may be via anterior, posterior, or combined approaches and with or without fusion. Anterior options include single or multilevel anterior cervical discectomy and fusion (ACDF), anterior cervical corpectomy and fusion (ACCF), and cervical disc replacement (CDR). Posterior options include laminectomy without fusion, laminectomy and instrumented fusion, and laminoplasty. Factors to consider when selecting the operative approach include location of cord compression, number of levels involved, sagittal alignment, instability, associated axial neck pain, and risk factors for pseudoarthrosis. 


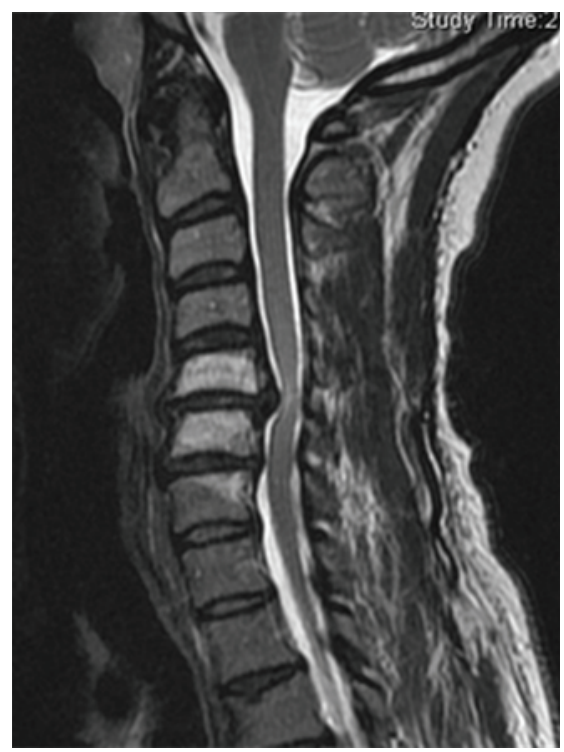

(a)

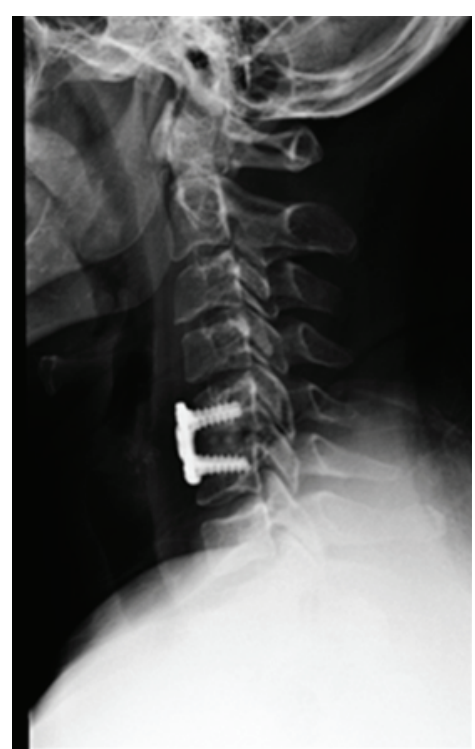

(b)

FIgURE 1: (a) Sagittal MRI demonstrating C5-6 extruded disc herniation. (b) Lateral radiograph of same patient after undergoing anterior cervical discectomy and fusion.

\section{Anterior Surgical Options}

The anterior surgical options can be used for both single level and multilevel disease. The anterior approach is generally favored with soft disc herniations, concomitant severe axial neck pain, kyphosis, and with 1-2 levels of involvement (Figure 1).

ACDF utilizes a Smith-Robinson approach to access the anterior surface of the cervical spine. After incision of the platysma, this approach involves little muscle disruption but opening of the pretracheal and prevertebral fascial planes to mobilize the midline structures of the neck. The decompression involves a thorough discectomy with removal of cartilaginous end plates and posterior osteophytes. A left-sided approach is preferred by some due to a more favorable course of the recurrent laryngeal nerve. Adequate decompression of the spinal cord may require removal of posterior osteophytes, partial corpectomy, or removal of the posterior longitudinal ligament (PLL); however all of these procedures increase the risk of injury to the spinal cord. ACCF is an alternative to multilevel ACDF and utilizes a similar approach, with either a transverse or longitudinal incision depending on number of levels. In this technique a central trough of vertebral body is progressively removed with a combination of a high-speed burr and rongeurs (Figure 2).

The trough is centered between the uncovertebral joints, which helps orient the trough over the spinal cord and ensure complete decompression. Care must be taken to avoid eccentric bone removal laterally, endangering the vertebral arteries. A thin shell of the remaining posterior wall and posterior longitudinal ligament can then be removed with microcurrettes and Kerrisons. Fusion with ACDF and ACCF may be achieved with various graft options, including autologous tricortical iliac crest graft, allograft, polyetheretheketone (PEEK), or metal cages or a combination of morsellized bone

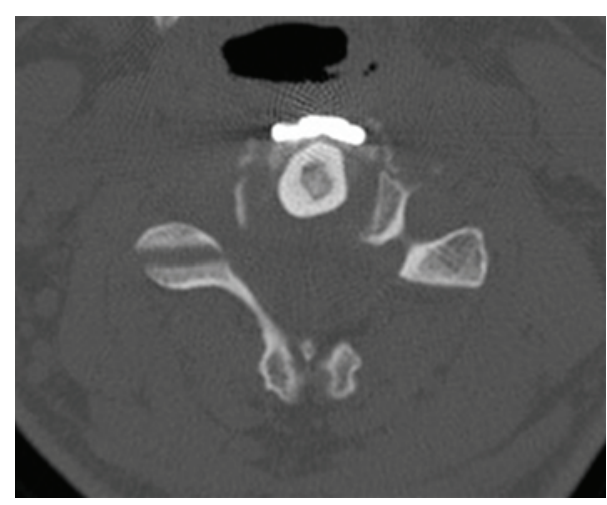

FIgure 2: Axial CT scan demonstrating fibula strut graft placed in central corpectomy trough.

from the corpectomy plus a structural allograft or cage. Plating is now common, especially with multilevel ACDF and ACCF $[7,8]$. Complications with the anterior approach include vertebral artery injury $(0.3 \%)$, esophageal injury $(0.2-$ $0.4 \%)$, wound infection $(0.2-1.4 \%)$, and dysphagia (28$57 \%$ ) [9]. The cause of dysphagia appears to be multifactorial, including traction on the superior laryngeal nerve, pharyngeal plexus, recurrent laryngeal nerve, and esophageal retraction. Risk factors for dysphagia include age $>60$, multiple levels, revisions, females, thick plates, and longer preop pain [10].

Advantages of ACDF or ACCF include ability to directly decompress offending structures, decompress the anterior spinal artery, restore cervical lordosis, and address axial neck pain. Multilevel ACDF is preferred in certain situations over ACCF where the compression is confined to the level of the disc spaces. Also, it is associated with a less blood loss and has a lower risk of graft kick out and catastrophic failure [11]. 


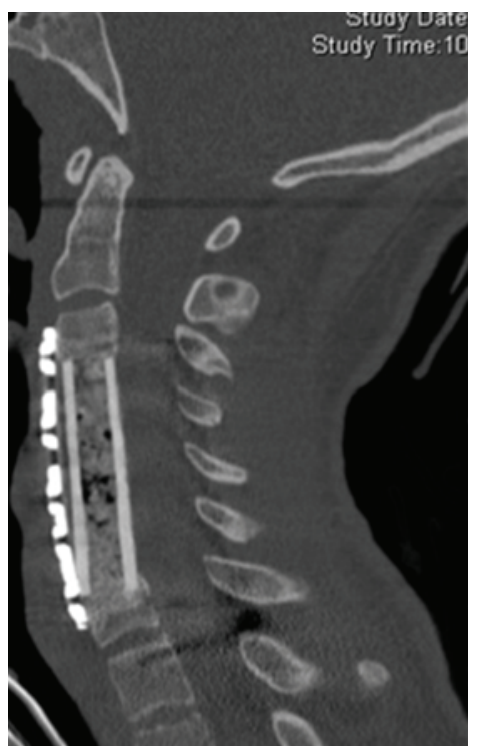

(a)

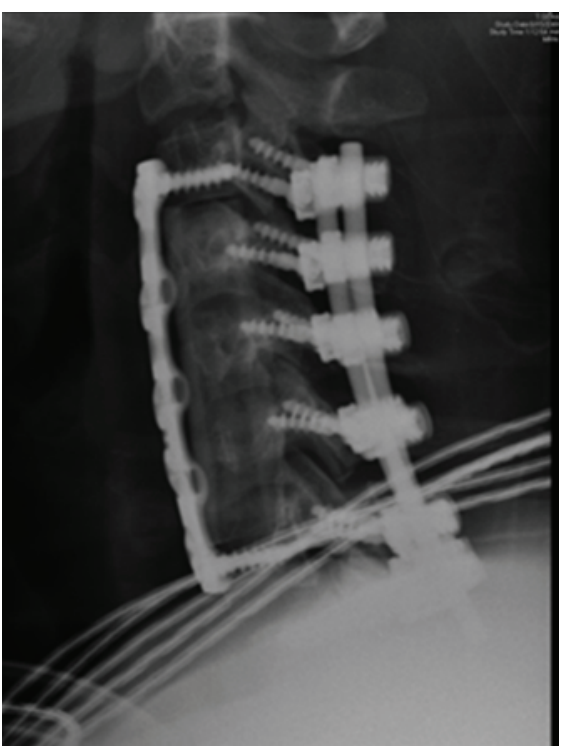

(b)

Figure 3: (a) Sagittal reconstructed CT scan of patient who underwent 3-level corpectomy. (b) Lateral radiograph of same patient. Posterior fusion was performed to increase stability of the construct.

However multilevel ACDF is associated with an increased risk of pseudarthrosis, as high as 54\% in three-level fusions [12]. Some surgeons use off-label recombinant human bone morphogenetic protein-2 (rhBMP-2) in these situations, but this should be undertaken with caution as there have been reports of airway compromise due to swelling [13]. ACCF is preferred when compression extends behind the vertebral bodies to ensure that all areas of compression are addressed. When multilevel corpectomies are performed, there is potential for significant plate failure and graft extrusion, so supplemental posterior instrumentation should be considered [14] (Figure 3).

Some have suggested that a potential benefit of ACCF is that fewer graft surfaces are required to fuse than multilevel ACDF (i.e., for a decompression at C4-5/C5-6, ACDF would require 4 surfaces to fuse versus 2 surfaces if treated with ACCF). Multiple studies have compared the fusion rates of ACCF and ACDF in an attempt to verify this benefit. Nirala et al. investigated 201 patients with multilevel noninstrumented anterior fusion and found that with more levels ACCF had a higher fusion rate than ACDF [15]. Another study investigated 52 patients with multilevel anterior fusion with autograft and plate fixation and found similar clinical and fusion rates between ACCF and ACDF [16]. With modern plating techniques, it appears that fusion rates are similar between the two techniques [17]. A hybrid technique, combining selected corpectomies and discectomies, can be utilized where there is both retrodiscal and retrovertebral compression. Such a construct can increase stability and obviate the need for posterior supplementation. Shen et al. investigated the pseudarthrosis rate of multilevel anterior cervical fusion with rhBMP-2 and allograft using a hybrid technique in 127 patients [18]. Overall pseudarthrosis rate was $10 \%$, with $4 \%$ for three levels, $17 \%$ for four levels, and $22 \%$ for five levels. Nonunions typically occurred at the lowest level.

CDR is another anterior option in cases where cord compression is confined to the retrodiscal region. As a nonfusion option, this may provide the theoretical benefit of decreasing adjacent segment degeneration. Buchowski et al. compared ACDF with CDR for myelopathy at a single level disc space [19]. These authors found similar improvement in neurologic status between the two groups at two years. Recently two-level CDR has come under investigation [20].

\section{Posterior Surgical Options}

The posterior surgical options are generally utilized for multilevel compression, such as in cases of congenital stenosis, older patients with advanced multilevel spondylosis, and certain cases of ossification of the posterior longitudinal ligament (OPLL) [21, 22]. The posterior approach relies on decompression through both direct removal of offending posterior structures and indirectly, through spinal cord translation posteriorly [23]. Therefore when spinal cord compression is from anterior structures, patients should have maintenance of lordosis or correctable kyphosis to permit adequate indirect decompression [24]. Posterior approaches utilize a midline approach through the posterior cervical skin and musculature followed by subperiosteal dissection of the selected levels. Extent of dissection laterally over the facets is dependent on whether a concomitant fusion is to be performed.

Laminoplasty increases the effective diameter of the spinal canal while preserving the posterior elements of the cervical spine as a biologic covering over the spinal canal. Laminoplasty requires at least 10 degrees of lordosis to allow 


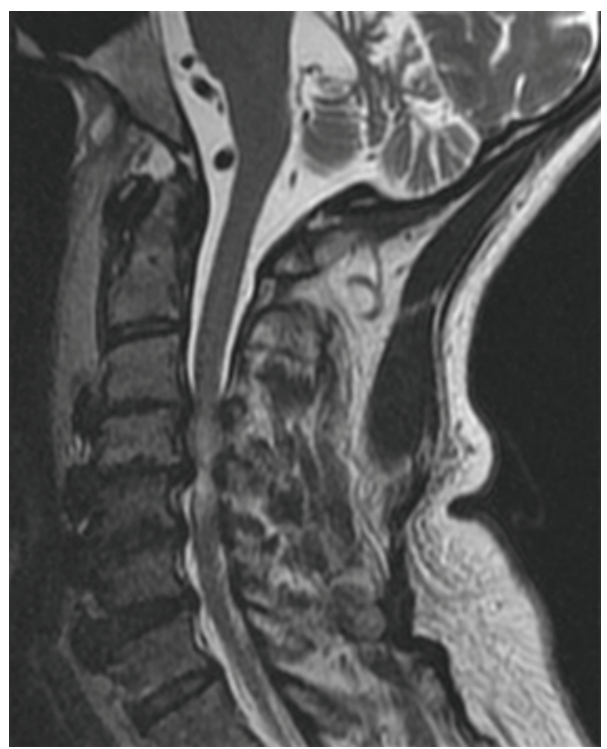

(a)

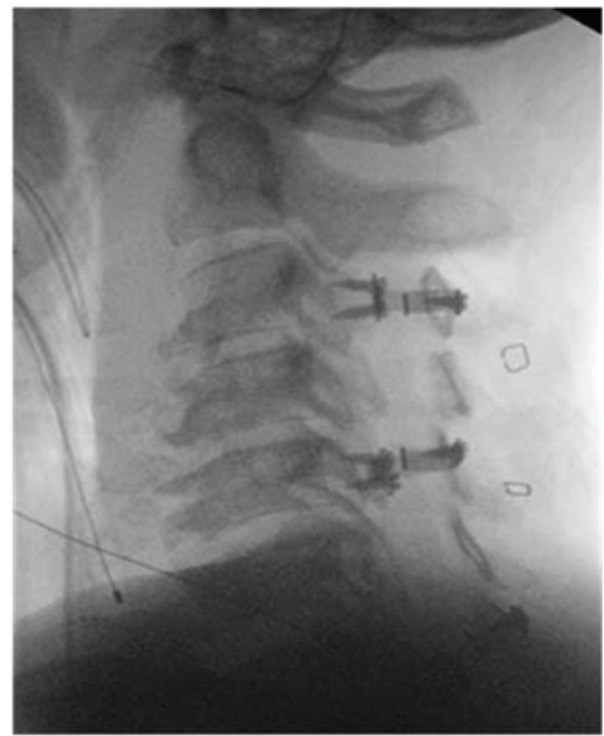

(b)

FIgURE 4: (a) Sagittal MRI of a patient with multilevel stenosis and preserved lordosis. (b) Lateral radiograph of same patient after canalexpanding laminoplasty.

posterior shift of the spinal cord for indirect decompression [25]. In the open-door technique, two troughs are created at the junction of the lateral masses and lamina with the use of a high-speed burr. One side is completed with microcurrettes or Kerrison rongeurs, the other side left with a thin shell of bone that is then "greensticked" creating a hinge. Once opened, the door can be kept patent with a variety of techniques including suture or wiring of the spinous process to the facet joint, by insertion of a spacer within the opening, or with miniplate and screw fixation (Figure 4).

The main advantage of laminoplasty is the avoidance of fusion. Despite this, patients do experience decreased range of motion postoperatively of up to $50 \%$ [26]. Since fusion is not performed, the patient requires preexisting cervical stability, and upright and/or flexion-extension radiographs should be considered to confirm this preoperatively. Laminoplasty has been compared to corpectomy and laminectomy with fusion and has been shown to have similar clinical outcomes to both $[27,28]$. Complications include C5 nerve root palsy, kyphosis, wound complications, and persistent or new axial neck pain $[26,29]$.

Laminectomy involves removal of the lamina and ligamentum flavum over the desired levels and can be performed with or without fusion and instrumentation. Laminectomy without fusion is generally restricted to patients with preserved lordosis who are poor candidates for fusion, since significant rates of progressive postoperative kyphosis have been reported [30, 31]. Instrumented fusion should be utilized for most cases, especially in circumstances of correctable kyphosis and instability. A multitude of instrumentation and screw techniques as well as graft choices exist and can be utilized at the discretion of the individual surgeon. Complications of multilevel laminectomy and fusion include C5 nerve root palsy, wound complications, and hardware failure [2]. In cases of long multilevel laminectomy and fusion, caudal fixation in the C7 lateral masses is suboptimal due to their small size. Pedicle screws at either C7 or the top 2 thoracic vertebrae decrease the chance of distal fixation failure in these long constructs (Figure 5).

With the aforementioned considerations in mind, the primary indication for a combined anterior and posterior approach is multilevel compression in the setting of fixed kyphosis, especially if 2 or more corpectomies must be performed. It can also be considered in patients with localized disease and poor bone quality or high risk for pseudarthrosis. Konya et al. reported on 40 patients treated with combined anterior and posterior approaches for CSM [32]. All patients had three- to four-level disease. At one-year follow-up neurologic function was improved in all patients with a $97.5 \%$ fusion rate with no reported instrumentation complications. The exact number of levels to consider combined approach is still debated.

\section{Comparative Efficacy}

Recently a systematic review sponsored by the American Association of Neurological Surgeons (AANS)/the Congress of Neurological Surgeons (CNS) was performed to develop evidence-based guidelines for choosing among the available surgical options for treatment of CSM [17]. The National Library of Medicine and Cochrane Databases were queried using MeSH headings and keyword regarding anterior and posterior surgery and CSM. An evidentiary table was assembled to summarize the quality of evidence from I to III (lowest). Recommendations were formulated containing degree of strength based on Scottish Intercollegiate Guidelines. Most of the manuscripts were found to be Class III. The results of the paper were that ACDF, ACCF, laminoplasty, 


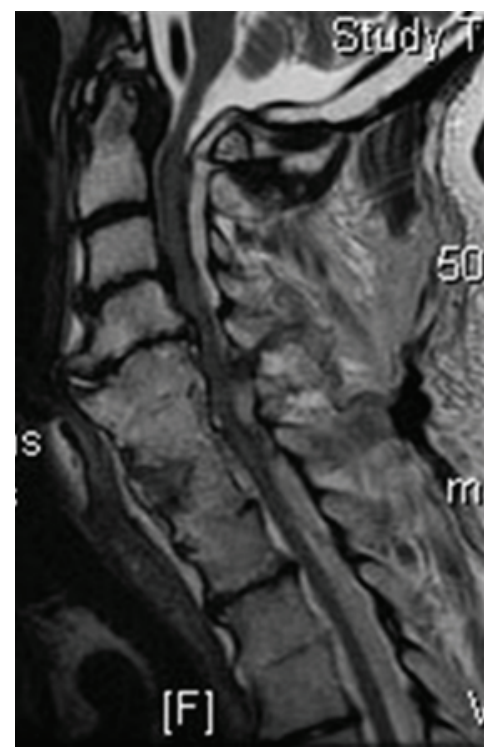

(a)

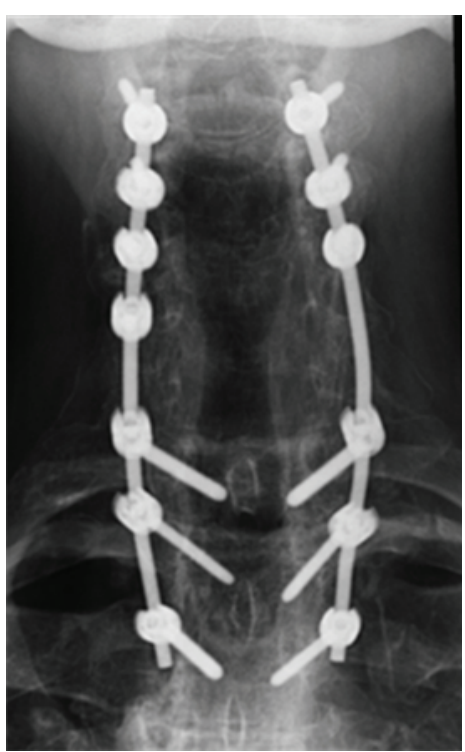

(b)

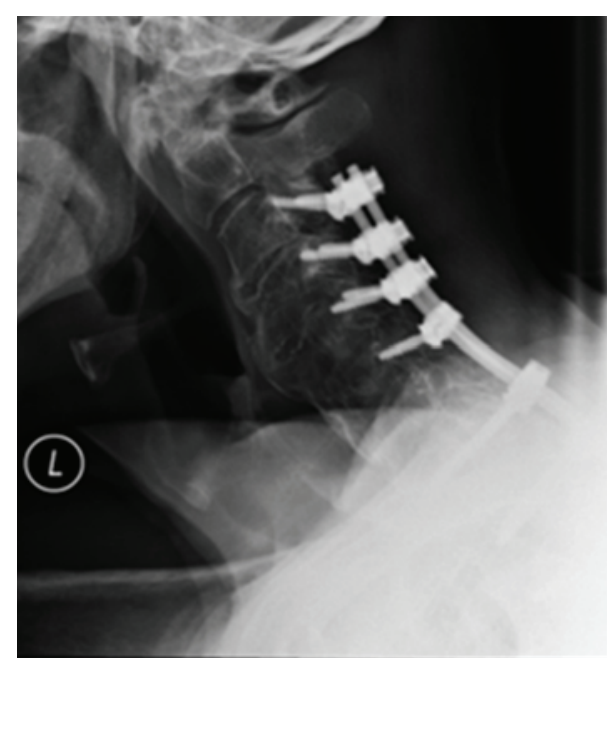

(c)

FIGURE 5: (a) Sagittal MRI of a patient with severe multilevel spondylosis and stenosis. (b-c) Anteroposterior (b) and lateral (c) radiographs of same patient after multilevel laminectomy and fusion. Note that distal fixation was achieved with pedicle screws which have increased pullout resistance compared with lateral mass fixation.

laminectomy, and laminectomy with fusion all yielded similar near term functional improvements for CSM. Laminectomy without fusion, however, is associated with late deterioration. Another recent systematic review of retrospective cohort studies showed that ACCF, ACDF, laminoplasty, and laminectomy and fusion yielded similar neurologic recovery [33]. The major differences between the groups were the associated complications. Therefore it appears that, given the available literature, the choice of surgical approach will be more dependent on the individual patient factors described previously than the superiority of any one surgical option. This clinical equipoise has been the motivating factor for interest in pursuing a prospective randomized clinical trial and for the distinction of CSM as one of the national health research priorities for comparative effectiveness research by the Institute of Medicine (Medicine Io; Initial National Priorities for Comparative Effectiveness Research; http://www. iom.edu/. Accessed May 31, 2011).

\section{Conclusions}

Cervical spondylotic myelopathy is a progressive disease that often requires surgical intervention. A variety of surgical options exist, including anterior and posterior approaches with and without fusion. Evidence-based review has not clearly shown one technique to be clinically superior to another. Therefore decision-making will depend on individual patient factors and associated approach-related complications. Factors to consider include location of cord compression, number of levels involved, sagittal alignment, instability, associated axial neck pain, and risk factors for pseudoarthrosis.

\section{References}

[1] M. Matsumoto, Y. Fujimura, N. Suzuki et al., "MRI of cervical intervertebral discs in asymptomatic subjects," The Journal of Bone and Joint Surgery B, vol. 80, no. 1, pp. 19-24, 1998.

[2] R. D. Rao, B. L. Currier, T. J. Albert et al., "Degenerative cervical spondylosis: clinical syndromes, pathogenesis, and management," The Journal of Bone and Joint Surgery A, vol. 89, no. 6, pp. 1360-1378, 2007.

[3] L. M. Teresi, R. B. Lufkin, and M. A. Reicher, "Asymptomatic degenerative disk disease and spondylosis of the cervical spine: MR imaging," Radiology, vol. 164, no. 1, pp. 83-88, 1987.

[4] S. Nurick, "The natural history and the results of surgical treatment of the spinal cord disorder associated with cervical spondylosis," Brain, vol. 95, no. 1, pp. 101-108, 1972.

[5] M. Matsumoto, K. Chiba, M. Ishikawa, H. Maruiwa, Y. Fujimura, and Y. Toyama, "Relationships between outcomes of conservative treatment and magnetic resonance imaging findings in patients with mild cervical myelopathy caused by soft disc herniations," Spine, vol. 26, no. 14, pp. 1592-1598, 2001.

[6] P. G. Matz, L. T. Holly, P. V. Mummaneni et al., "Anterior cervical surgery for the treatment of cervical degenerative myelopathy," Journal of Neurosurgery: Spine, vol. 11, no. 2, pp. 170173, 2009.

[7] J. C. Wang, P. W. McDonough, K. K. Endow, and R. B. Delamarter, "Increased fusion rates with cervical plating for two-level anterior cervical discectomy and fusion," Spine, vol. 25, no. 1, pp. 41-45, 2000.

[8] J. C. Wang, P. W. McDonough, K. Endow, L. E. A. Kanim, and R. B. Delamarter, "The effect of cervical plating on single-level anterior cervical discectomy and fusion," Journal of Spinal Disorders, vol. 12, no. 6, pp. 467-471, 1999.

[9] A. H. Daniels, K. D. Riew, J. U. Yoo et al., "Adverse events associated with anterior cervical spine surgery," Journal of 
the American Academy of Orthopaedic Surgeons, vol. 16, no. 12, pp. 729-738, 2008.

[10] L. H. Riley III, R. L. Skolasky, T. J. Albert, A. R. Vaccaro, and J. G. Heller, "Dysphagia after anterior cervical decompression and fusion: prevalence and risk factors from a longitudinal cohort study," Spine, vol. 30, no. 22, pp. 2564-2569, 2005.

[11] J. C. Wang, R. A. Hart, S. E. Emery, and H. H. Bohlman, "Graft migration or displacement after multilevel cervical corpectomy and strut grafting," Spine, vol. 28, no. 10, pp. 1016-1021, 2003.

[12] M. L. Swank, G. L. Lowery, A. L. Bhat, and R. F. McDonough, "Anterior cervical allograft arthrodesis and instrumentation: multilevel interbody grafting or strut graft reconstruction," European Spine Journal, vol. 6, no. 2, pp. 138-143, 1997.

[13] J. B. Stachniak, J. D. Diebner, E. S. Brunk, and S. M. Speed, "Analysis of prevertebral soft-tissue swelling and dysphagia in multilevel anterior cervical discectomy and fusion with recombinant human bone morphogenetic protein-2 in patients at risk for pseudarthrosis: clinical article," Journal of Neurosurgery: Spine, vol. 14, no. 2, pp. 244-249, 2011.

[14] A. R. Vaccaro, S. P. Falatyn, G. J. Scuderi et al., "Early failure of long segment anterior cervical plate fixation," Journal of Spinal Disorders, vol. 11, no. 5, pp. 410-415, 1998.

[15] A. P. Nirala, M. Husain, and D. K. Vatsal, "A retrospective study of multiple interbody grafting and long segment strut grafting following multilevel anterior cervical decompression," British Journal of Neurosurgery, vol. 18, no. 3, pp. 227-232, 2004.

[16] J. C. Wang, P. W. McDonough, K. K. Endow, and R. B. Delamarter, "A comparison of fusion rates between single-level cervical corpectomy and two-level discectomy and fusion," Journal of Spinal Disorders, vol. 14, no. 3, pp. 222-225, 2001.

[17] P. V. Mummaneni, M. G. Kaiser, P. G. Matz et al., "Cervical surgical techniques for the treatment of cervical spondylotic myelopathy," Journal of Neurosurgery: Spine, vol. 11, no. 2, pp. 130-141, 2009.

[18] H. X. Shen, J. M. Buchowski, J. S. Yeom, G. Liu, N. Lin, and K. D. Riew, "Pseudarthrosis in multilevel anterior cervical fusion with rhBMP-2 and allograft: analysis of one hundred twentyseven cases with minimum two-year follow-up," Spine, vol. 35, no. 7, pp. 747-753, 2010.

[19] J. M. Buchowski, P. A. Anderson, L. Sekhon, and K. D. Riew, "Cervical disc arthroplasty compared with arthrodesis for the treatment of myelopathy. Surgical technique," The Journal of Bone and Joint Surgery, vol. 91, supplement 2, pp. 223-232, 2009.

[20] Y. Wang, Z. Xuesong, X. Songhua, L. Ning, W. Zheng, and Z. $\mathrm{Mi}$, "Clinical report of cervical arthroplasty in management of spondylotic myelopathy in Chinese," Journal of Orthopaedic Surgery and Research, vol. 1, no. 1, article 13, 2006.

[21] S. Hukuda, T. Mochizuki, and M. Ogata, "Operations for cervical spondylotic myelopathy. A comparison of the results of anterior and posterior procedures," The Journal of Bone and Joint Surgery B, vol. 67, no. 4, pp. 609-615, 1985.

[22] P. G. Matz, P. A. Anderson, M. W. Groff et al., "Cervical laminoplasty for the treatment of cervical degenerative myelopathy," Journal of Neurosurgery: Spine, vol. 11, no. 2, pp. 157$169,2009$.

[23] T. Sodeyama, S. Goto, M. Mochizuki, J. Takahashi, and H. Moriya, "Effect of decompression enlargement laminoplasty for posterior shifting of the spinal cord," Spine, vol. 24, no. 15, pp. 1527-1532, 1999.

[24] K. Suda, K. Abumi, M. Ito, Y. Shono, K. Kaneda, and M. Fujiya, "Local kyphosis reduces surgical outcomes of expansive opendoor laminoplasty for cervical spondylotic myelopathy," Spine, vol. 28, no. 12, pp. 1258-1262, 2003.
[25] A. Yamazaki, T. Homma, S. Uchiyama, Y. Katsumi, and H. Okumura, "Morphologic limitations of posterior decompression by midsagittal splitting method for myelopathy caused by ossification of the posterior longitudinal ligament in the cervical spine," Spine, vol. 24, no. 1, pp. 32-34, 1999.

[26] J. K. Ratliff and P. R. Cooper, "Cervical laminoplasty: a critical review," Journal of Neurosurgery, vol. 98, no. 3, supplement, pp. 230-238, 2003.

[27] C. C. Edwards II, J. G. Heller, and H. Murakami, "Corpectomy versus laminoplasty for multilevel cervical myelopathy: an independent matched-cohort analysis," Spine, vol. 27, no. 11, pp. 1168-1175, 2002.

[28] P. A. Anderson, P. G. Matz, M. W. Groff et al., "Laminectomy and fusion for the treatment of cervical degenerative myelopathy," Journal of Neurosurgery: Spine, vol. 11, no. 2, pp. 150-156, 2009.

[29] N. Hosono, K. Yonenobu, and K. Ono, "Neck and shoulder pain after laminoplasty: a noticeable complication," Spine, vol. 21, no. 17, pp. 1969-1973, 1996.

[30] S. Matsunaga, T. Sakou, and K. Nakanisi, "Analysis of the cervical spine alignment following laminoplasty and laminectomy," Spinal Cord, vol. 37, no. 1, pp. 20-24, 1999.

[31] T. C. Ryken, R. F. Heary, P. G. Matz et al., "Cervical laminectomy for the treatment of cervical degenerative myelopathy," Journal of Neurosurgery: Spine, vol. 11, no. 2, pp. 142-149, 2009.

[32] D. Konya, S. Ozgen, A. Gercek, and M. N. Pamir, "Outcomes for combined anterior and posterior surgical approaches for patients with multisegmental cervical spondylotic myelopathy," Journal of Clinical Neuroscience, vol. 16, no. 3, pp. 404409, 2009.

[33] M. R. A. Cunningham, S. Hershman, and J. Bendo, "Systematic review of cohort studies comparing surgical treatments for cervical spondylotic myelopathy," Spine, vol. 35, no. 5, pp. 537-543, 2010. 


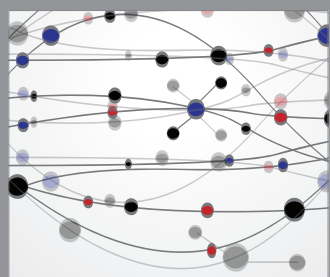

The Scientific World Journal
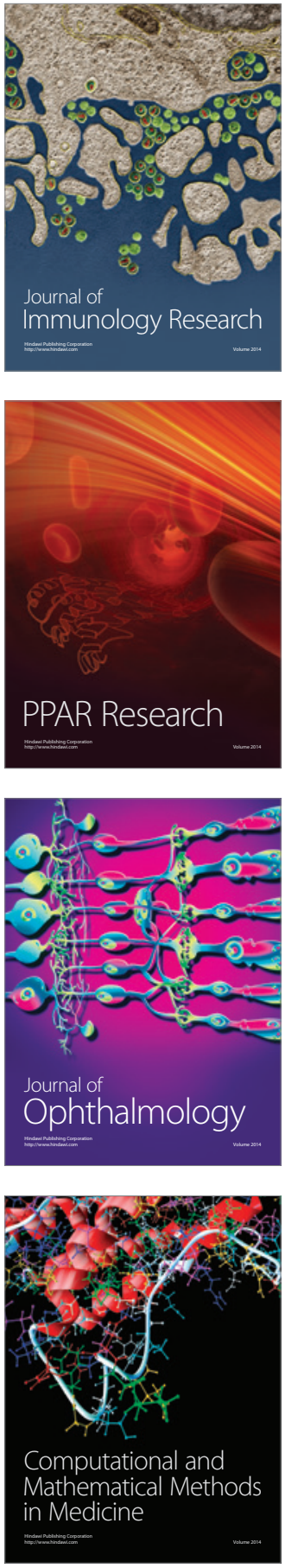

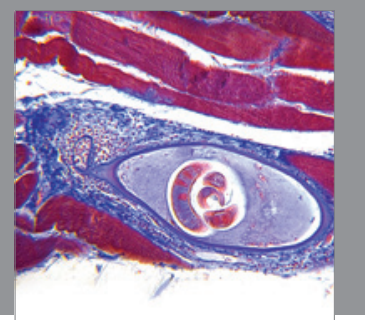

Gastroenterology

Research and Practice
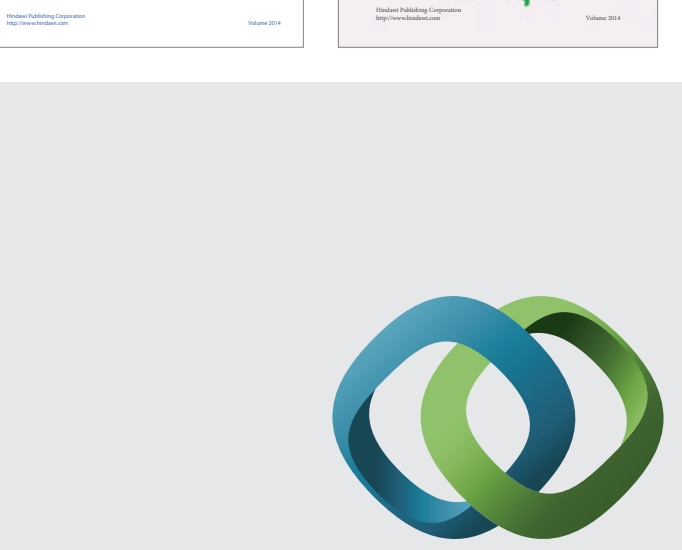

\section{Hindawi}

Submit your manuscripts at

http://www.hindawi.com
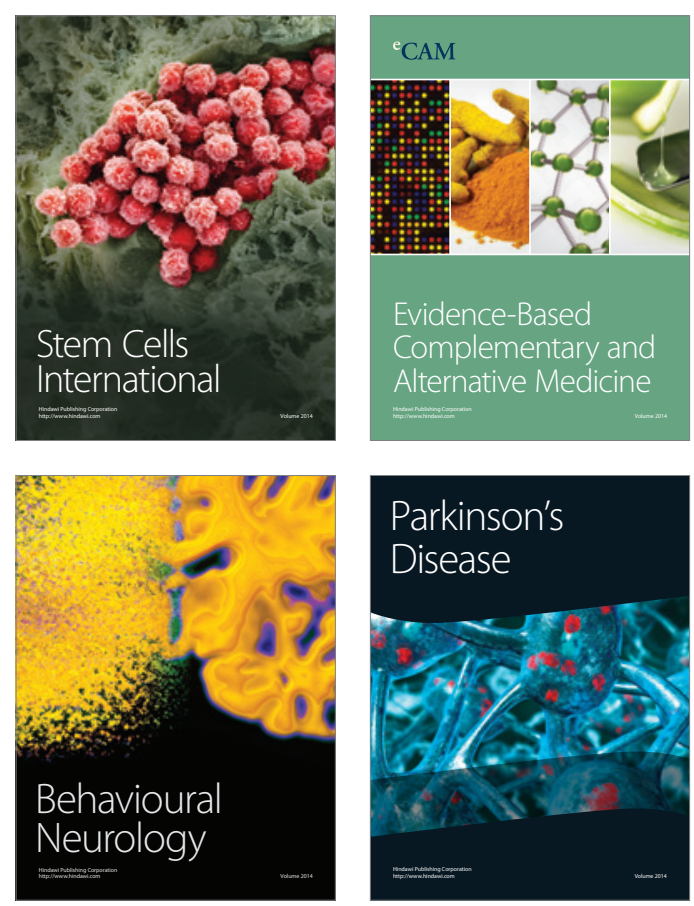

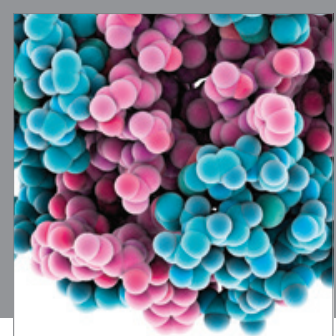

Journal of
Diabetes Research

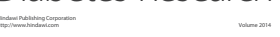

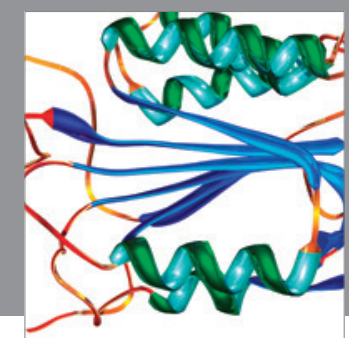

Disease Markers
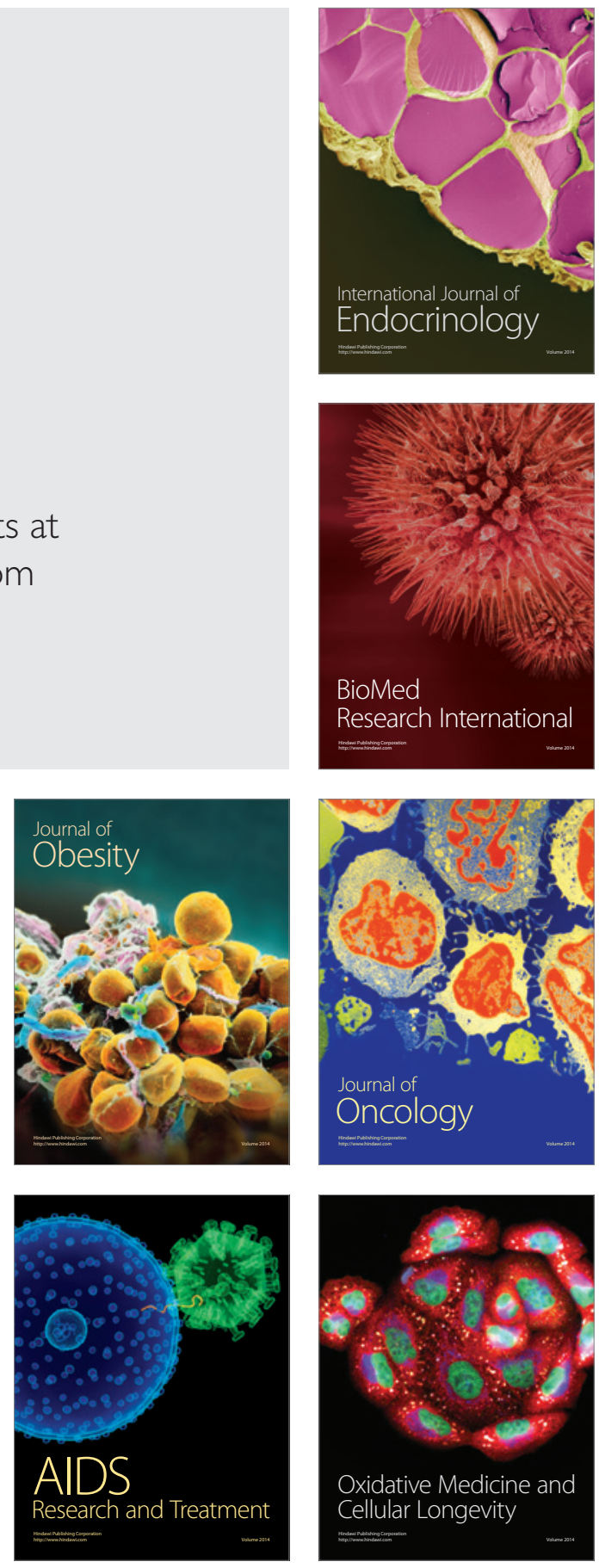